\title{
Jean-Fernand Bédia, Les écritures africaines face à la logique actuelle du comparatisme
}

\section{Jean-François Plamondon}

\section{(2) OpenEdition}

10 Journals

\section{Édition électronique}

URL : http://journals.openedition.org/studifrancesi/1644

DOI : 10.4000/studifrancesi. 1644

ISSN : 2421-5856

Éditeur

Rosenberg \& Sellier

\section{Édition imprimée}

Date de publication : 1 novembre 2014

Pagination : 642-643

ISSN : 0039-2944

\section{Référence électronique}

Jean-François Plamondon, « Jean-Fernand Bédia, Les écritures africaines face à la logique actuelle du comparatisme », Studi Francesi [En ligne], 174 (LVIII | III) | 2014, mis en ligne le 01 novembre 2014, consulté le 18 septembre 2020. URL : http://journals.openedition.org/studifrancesi/1644 ; DOI : https://doi.org/10.4000/studifrancesi.1644

Ce document a été généré automatiquement le 18 septembre 2020.

\section{(c)}

Studi Francesi è distribuita con Licenza Creative Commons Attribuzione - Non commerciale - Non opere derivate 4.0 Internazionale. 


\title{
Jean-Fernand Bédia, Les écritures africaines face à la logique actuelle du comparatisme
}

\author{
Jean-François Plamondon
}

\section{RÉFÉRENCE}

JEAN-FERNAND BÉDIA, Les écritures africaines face à la logique actuelle du comparatisme, Paris, L'Harmattan, 2012, pp. 188.

1 C'est probablement le dernier livre de 2012 qui sera recensé dans cette revue, mais ce n'est certainement pas le moins intéressant. Comme quoi, parfois, le hasard de nos recherches peut nous conduire vers de belles surprises. Jean-Fernand Bédia est professeur à l'Université de Bouaké, en Côte d'Ivoire. Il propose un essai critique audacieux avec lequel on pourra certes être en désaccord mais qui aura le mérite de lancer un débat théorique dans le champ des littératures comparées. Le texte est sérieux, la réflexion est d'une grande qualité et les références témoignent d'une recherche de haut niveau. Bédia rappelle au souvenir de son lecteur l'actualité du texte de René Étiemble, Comparaison n'est pas raison (1963), pour poser l'édifice de sa réflexion. Ce texte revient en filigrane tout au long de l'essai sur le comparatisme que Bédia définit comme un exercice de lecture «totalisant des paramètres sociologiques et géopolitiques qui expliquent aussi bien l'identité et l'évolution des littératures produites par les peuples depuis la fin de la colonisation». (p. 12) Sans parler de déconstruction, Bédia exige tout de même que l'on réévalue «les conditions et les terminologies de la critique comparatiste, qui conduisent à l'idéologisation consciente ou inconsciente des enjeux de la littérature comparée» (p. 13), l'enjeu de cette entreprise est crucial puisqu'il s'agit de «se demander si l'intérêt manifesté pour ces traditions littéraires conforte ou infirme un certain nombre d'idées reçues relatives aux civilisation non européennes» (p. 13). Nos outils de recherche, nos concepts intellectuels issus de nos traditions littéraires, pensés à partir de notre production 
littéraire sont-ils adaptés à la réalité culturelle des différents pays et des nombreuses cultures africaines? N'y a-t-il pas à craindre parfois aussi que notre discours comparatiste cloisonne deux cultures plutôt que de les rapprocher? Pour Bédia, il devrait y avoir un échange entre les cultures l'une apportant à l'autre, et réciproquement, une partie de son savoir, de son imaginaire, de son esthétique. Ce faisant, nous aurions une culture de partage. Mais il est avéré que notre monde universitaire, qui devrait être universaliste, base certains critères de qualité littéraire en fonction des espaces géographiques où sont produits les textes, et que l'intérêt de la lecture de certains textes se profile à partir de critères anthropologiques. Si ces observations ne sont pas nouvelles, leurs récurrences permettent toutefois de juger de la profondeur du problème. Bernard mouRALIs l'avait déjà exprimé dans L'illusion de l'altérité (2007), Bédia rappelle quant à lui que les grands critiques institutionnels parisiens, comme Gérard Genette, n'intègrent jamais à leur corpus d'analyse un texte qui ne soit pas français hexagonal. La langue française comme paradigme constituant d'un corpus ne devrait-elle pas suffire à elle-même? Après tout, la littérature ne devrait-elle pas être évaluée en fonction du travail qu'elle fait sur la langue? Pour Bédia, «il n'est pas exagéré de dire qu'Amos Tutuola et plus encore Ahmadou Kourouma ont provoqué une révolution esthétique littéraire, respectivement avec L'Ivrogne dans la brousse et Les Soleils des indépendances. Le type d'écriture romanesque que ces textes ont initié était alors inédit» (pp. 55-56). Mais si ces textes sont bien connus des chercheurs en littératures de la francophonie, ou s'ils sont bien connus de certains comparatistes, ils ont laissé bien peu de place dans le discours critique qui construit notamment, et ce n'est pas rien, le canon littéraire de langue française. Et c'est un des éléments que dénonce le professeur de Bouaké: «on ne peut plus continuer de penser les théories du roman et de la littérature en général, sans faire allusion aux apports des écrivains des territoires autres que ceux du monde occidental. La raison en est que le modèle esthétique du genre littéraire au $\mathrm{xxl}^{\mathrm{e}}$ siècle sera indissociable de l'évolution des manières de se représenter le monde; des représentations consécutives au multiculturalisme qui caractérise incontestablement autant les États-nations que l'humanité globale appréhendée sous la perspective actuelle de la mondialisation» (pp. 89-90). Le propos me semble tout-à-fait pertinent, il est audacieux et je souhaite qu'il se réalise. Mais il est révolutionnaire et l'ère des révolutions est passée en France. Cela implique en effet que la périphérie ait le droit de cité dans la définition du centre et que le centre accepte cette définition. Est-ce que le centre, lire ici Paris, est prêt à accepter que l'on intègre à son univers symbolique, un propos issu d'une réflexion qui n'est pas la sienne? Sans doute, mais il faut du temps car, pour reprendre le titre énigmatique d'un essai de Pierre Falardeau, Les boufs sont lents mais la terre est patiente. En d'autres mots, ne désespérons pas, le travail se fait, le sillon des littératures francophones s'est tracé lentement et les voix s'élèvent doucement sous le soleil qui les mûrit. Peut-être que le suc de leurs fruits les plus mûrs sauront un jour flatter le palais des princes parisiens. Et cela n'est aucunement exclu. Ceci dit, si j'ai aimé le livre de BÉDIA, c'est que je lui ai trouvé des vertus universelles, et que sa réflexion sur les écritures africaines ouvrait à d'aussi belles rêveries dans d'autres espaces géo-anthropologiques et j'en remercie son auteur. 